\title{
Mothers' Satisfaction with Institutional Delivery Service in Public Health Facilities of Omo Nada District, Jimma Zone
}

\author{
Biniyam Haile Tadesse, Negalign Birhanu Bayou, Gebeyehu Tsega Nebeb* \\ Department of Health Economics, Management and Policy, Institute of Health, Jimma University, Jimma, Ethiopia \\ Email address: \\ binitit@gmail.com (B. H. Tadesse), negenu@gmail.com (N. B. Bayou), gebishtsgmail.com (G. T. Nebeb) \\ ${ }^{*}$ Corresponding author
}

To cite this article:

Biniyam Haile Tadesse, Negalign Birhanu Bayou, Gebeyehu Tsega Nebeb. Mothers' Satisfaction with Institutional Delivery Service in Public Health Facilities of Omo Nada District, Jimma Zone. Clinical Medicine Research. Vol. 6, No. 1, 2017, pp. 23-30.

doi: 10.11648/j.cmr.20170601.13

Received: January 19, 2017; Accepted: January 31, 2017; Published: March 2, 2017

\begin{abstract}
Assessment of client satisfaction has become an administrative and a practical reality; it is important measure of the quality of services. Satisfaction studies provide feedback on how well the service is functioning according to clients' perception and what changes might be required to meet clients' expectation. Satisfaction affects service utilization; satisfied mothers will have optimum utilization of delivery service. This study assessed satisfaction with institutional delivery service and factors affecting their satisfaction, among mothers who gave birth in public health centers of Omo Nada district, south west Ethiopia. A facility based cross-sectional study was conducted on 391mothers who gave birth in selected public health centers of Omo Nada district, south west of Addis Ababa. The total sample was allocated to four health centers, based on expected pregnancy in their catchment area. Sample mothers were selected using systematic random sampling, list of mothers registered on delivery registration books of each health center were used as a sampling frame. Pre-tested structured questionnaire was used, 5 data collectors with diploma were recruited. Collected data were entered in to EPIDATA 3.0, and exported to SPSS version 16. Bivariate and multivariate logistic regression analyses were conducted. The overall satisfaction with institutional delivery service was 255(65.2\%). Major satisfaction was recorded with supportiveness of the provider and cleanliness of delivery room. According to multivariate logistic regression analysis result, mothers who had ANC follow up had two fold increased satisfaction, $[\mathrm{AOR}=2.05,95 \%$ CI 1.33, 4.75]. Those who planned their pregnancy were 2.85 times more likely satisfied than those did not, $[\mathrm{AOR}=2.85$ with $95 \% \mathrm{CI} 1.56,5.21]$. This study showed ANC attendance, utilization of maternity waiting home (MWH) service, planned status of the pregnancy, distance and cleanliness of the toilet during delivery service were significant predicators of mothers' satisfaction with the service. Utilization of MWH and ANC attendance during pregnancy significantly increases mothers' satisfaction with institutional delivery service. On the other hand, mothers with unplanned pregnancy showed decreased satisfaction.
\end{abstract}

Keywords: Mothers' Satisfaction, Institutional Delivery, Omo Nada, Jimma Zone

\section{Introduction}

The health of women is an important contributing factor to the overall health of any nation; Maternal health care service is one of the most effective health interventions for preventing maternal morbidity and mortality. Skilled birth attendance during pregnancy is commonly used indicator of health system effectiveness [1,2].

Ensuring women's access to a continuum of care, including appropriate management of pregnancy, delivery and the postpartum period together with access to life-saving obstetric care when complications arise is important to lower health risks and mortality among mothers [3]. To decrease maternal morbidity and mortality, strong health systems offering accessible, quality and satisfactory maternal health care is needed $[4,5]$.

Approximately $74 \%$ of maternal deaths could be averted, if women had access to essential maternity and basic health care service. About $13-33 \%$ of maternal deaths could be prevented by using facility based skilled birth attendance [6]. Increasing institutional delivery is important proven 
intervention to reduce health risks and mortality among mothers [7].

Worldwide, $63.1 \%$ of births were attended by a skilled health care worker. Although virtually all births (100\%) were attended by skilled health care personnel in the more developed countries, the corresponding figure is $59.1 \%$ in developing countries and only $34.3 \%$ in the least developed countries. In Africa and Asia, only $46.5 \%$ and $60.8 \%$, respectively, of women gave birth with the help of a skilled attendant [8].

Ethiopia is one of Sub-Saharan African countries with high maternal mortality ratio and low institutional delivery coverage. With Maternal Mortality Ratio (MMR) of 676 per 100,000 live births, $12 \%$ skilled birth attendance and 19,000 maternal deaths per annum $[9,10]$.

Recent efforts to reduce maternal mortality have focused primarily on training and deploying skilled birth attendants, construction of health centers and hospitals, and upgrading emergency obstetric care facilities [11]. Beside the above efforts, institutional delivery service must consider client satisfaction, which has not been considered much. Satisfied mother makes optimum use of maternal health services [12].

The current potential health service coverage of Ethiopia is $90 \%$ [13]), but institutional delivery service coverage shows slight improvement with $0.53 \%$ annual increase [14]. Potential access of health facilities will not necessarily guarantee utilization health services; utilization also depends on clients willingness to access the service and their satisfaction (previous experience and perception) of the service $[15,16]$. Effectiveness of health service is severely limited without consumers satisfaction and proper utilization of health services [16].

Even though important inroads have been made to improve access and quality of care through local and global initiatives skilled delivery attendance coverage did not significantly increase in the last decade. The progress is much slower, and utilization is much lower, for institutional delivery service [5].

Implementation of institutional delivery service depends on: presence of a health worker with midwifery skills who can either provide essential obstetric care; availability of medical supplies, equipment and infrastructures [17]. In the least developed countries, insufficient resources have been dedicated to maternal health care. This result: absence of such a facility; poor quality and condition of health centers and hospitals; absence of skilled health personnel or personnel with low skills levels. All these and other client and provider related factors negatively affect client institutional delivery service utilization and mothers' satisfaction with the service [5].

Currently assessment of client satisfaction has become an administrative and a practical reality [18]. Client satisfaction is important measure of the quality of medical services because it gives information on the provider's success at meeting those client values. The assessment of client satisfaction adds an important 'consumer' perspective to evaluations. Feedback from clients can influence the whole quality improvement agenda within the institution or organization [19].

Studying implementation of institutional delivery service from client perspective will provide systematic information for service providers, decision makers, local planners and other stakeholders that help understand how well the service is functioning according to clients' perception, and what changes might be required to meet clients' expectation as well as to increase utilization of the service by the target population.

Moreover, this study serves both knowledge generation and program improvement purpose. Findings of this study can be used by local planers and decision makers to fine tune quality of institutional delivery service. It can also serve as a base line data for researchers to conduct further studies.

The objective of this study was to assess mothers' level of satisfaction with institutional delivery service and factors that affect their level of satisfaction, among mothers who gave birth in public health facilities of Omo Nada district, Jimma zone south west Ethiopia, 2014.

\section{Methods and Materials}

\subsection{Study Setting and Sampling}

A facility based cross-sectional study was conducted in Health Centers of Omo Nada district, Jimma Zone, Oromiya Regional State, south west Ethiopia, in June 2014. Omo Nada is one of the 18 districts of Jimma Zone which is located 290 kilometer south west of the capital Addis. According to the projection from national census of 2007 the total population is estimated to be 300,082 and total number of expected pregnancy is 11,103 by $2013 / 14$. There are 8 public health centers that provide institutional delivery service in the district [20].

A sample of 422, mothers who gave birth in public health centers (HC) of the district, was determined using statistical software Epi-info version 7.1. In sample size calculation $\mathrm{P}=50 \%$ (expected mothers' satisfaction with institutional delivery service) was taken and $10 \%$ expected non-response rate was also considered.

Four health centers $(50 \%$ of the total $\mathrm{HCs})$ were randomly selected using lottery method, and the selected HCs were primary sampling unit. The given sample size was proportionally allocated to the $4 \mathrm{HCs}$, based on the size of expected pregnant population that are served by respective Health Centers. A systematic random sampling technique was applied to draw allocated sample of mothers from each HCs. Delivery registration books that are found in HCs included in this study were used as sampling frame to select sample mothers that gave birth within the past six months in the specified health center. Sampling interval (k) was determined by dividing the sample allocated for each of particular HCs by total mothers who gave birth/registered on the registration book in the past six months. Selected mothers 
were traced using address filed on institutional delivery service registration book and their individual service card. Health extension workers and Women Development Army Leaders (WDAL) served as data collectors guide by showing residence of mothers included in the study. Mothers who were severely ill during the data collection period were excluded from the study.

Pre-test structured English questionnaire adapted from previous similar studies was used after translating in to Oromiffa, local language of the study area. The tool was organized in to three parts: the first part contains sociodemographic characteristics, obstetric history and the final part is satisfaction rating tool having 14 items that have five point Likert scales varying from strongly satisfied to strongly not satisfied.

Five data collectors with diploma in different field of study that had previous experience of data collection were recruited. Training was provided to data collectors and supervisor for two days. The supervisor was responsible to assist data collectors, check completeness and validity of questioners filled by data collectors on daily basis.

\subsection{Data Analysis}

Data were edited, cleaned, coded and entered in to EPIDATA 3.0, validated in double entry mode and exported to SPSS version 16. First the overall satisfaction, which is dependent variable, was computed by adding the mean score of 14 satisfaction items with 5 point Likert scale (ranging from strongly not Satisfied to Strongly Satisfied). The threshold score for satisfaction was determined using demarcation threshold formula, which is \{(total highest score-total lowest score)/2\} + Total lowest score [21, 22]. Mothers' overall satisfaction was categorized/dichotomized in to Satisfied and not satisfied. Bivariate and multivariate analysis were conducted to see the association and to measure the strength of between dependent and independent variables.

The association between dependent and independent variables was determined using odds ratio with $95 \%$ confidence interval. First bivariate logistic regression was performed to identify determinants of mothers' satisfaction with the service, variables that had p-value less than 0.25 were considered as significant candidates for the multivariate logistic regression analysis, and then multivariate logistic regression analysis that used backward stepwise method was applied to describe the relative effect of independent variables on overall client satisfaction.

$\mathrm{P}$ value $<0.05$ was considered statistically significant for both bivariate and multivariate logistic regression analysis.

\subsection{Ethical Issues}

Ethical clearance was obtained from Ethical Review Committee of College of Public Health and Medical Sciences of Jimma University. Support letters were obtained from Omo Nada district administration and Health office. Copy of the support letter was dispatched to each HC prior to the data collection. Participants were informed about purpose the study and how confidentiality will be maintained. Verbal consent was also obtained from each respondent involved in the study.

\section{Results}

\subsection{Study Participants}

Of 422 sample mothers selected from four HCs of Omo Nada district 391 were participated in the study, yielding $92.6 \%$ response rate. The mean age of respondents was 27.3 with a standard deviation (SD) \pm 5.2 , and $300(76.7 \%)$ respondents were between 20 and 34 years of age. Three hundred seventy five $(95.9 \%)$ were married, $314(87.0 \%)$ of the mothers were Muslims, and 183(46.8\%) were uneducated, only 20(5.1\%) had educational status of above 12 grade. Two hundred ninety nine $(76.5 \%)$ were from rural areas, and $150(38.4 \%)$ of mothers reside in less than 30 minute walking distance from the nearest $\mathrm{HC}$, the mean estimated walking distance hour of all study participants to reach the nearest health center was 52 minutes with SD of \pm 28 minutes (Table 1).

Table 1. Socio-demographic characteristics of study participants, Omo Nada district, south west Ethiopia, July 2014.

\begin{tabular}{|c|c|c|c|}
\hline \multicolumn{2}{|c|}{ Socio-demographic characteristics, $n=(391)$} & \multirow{2}{*}{$\begin{array}{l}\text { Frequency(n) } \\
45\end{array}$} & \multirow{2}{*}{$\begin{array}{l}\text { Percent (\%) } \\
11.5\end{array}$} \\
\hline \multirow{3}{*}{ Age of the Mother } & $<20$ Years & & \\
\hline & 20-34 Years & 300 & 76.7 \\
\hline & 34-49 Years & 46 & 11.8 \\
\hline \multicolumn{2}{|l|}{ Mean $( \pm S D)$ of age(year) } & $27.3( \pm 5.2)$ & \\
\hline \multirow[b]{2}{*}{ Ethnicity } & Oromo & 361 & 92.3 \\
\hline & Amhara & 22 & 5.6 \\
\hline \multirow{3}{*}{ Religion } & Muslim & 340 & 87.0 \\
\hline & Orthodox & 44 & 11.3 \\
\hline & Protestant & 7 & 1.8 \\
\hline \multirow{4}{*}{ Marital Status } & Single/Never married & 3 & 0.8 \\
\hline & Married & 375 & 95.9 \\
\hline & Widowed & 9 & 2.3 \\
\hline & Separated & 3 & 0.8 \\
\hline Mothers' education & Not Educated/Illiterate & 183 & 46.8 \\
\hline
\end{tabular}




\begin{tabular}{llll}
\hline Socio-demographic characteristics, $\mathbf{n}=(\mathbf{3 9 1})$ & Frequency(n) & Percent (\%) \\
\hline & Non-formal Education & 77 & 19.7 \\
& Primary Education (Grade 1-8) & 80 & 20.5 \\
& Secondary Education (Grade 9-12) & 31 & 7.9 \\
& Above Grade 12 & 20 & 5.1 \\
& Urban & 92 & 23.5 \\
Place of Residence & Rural & 299 & 76.5 \\
& Less than 30 minutes & 150 & 38.4 \\
Estimated Walking hours reach HC & 125 & 32.0 \\
& $30-60$ minutes & 76 & 19.4 \\
& $61-90$ minutes & 40 & 10.2 \\
\hline
\end{tabular}

\subsection{Obstetric History of Mothers}

The mean parity of respondents was 3.1 with $\mathrm{SD}$ of \pm 1.7 , and 223(76.7\%) of mothers have 2-4 children. Two hundred ninety eight $(76.25 \%)$ mothers, had delivered only one child at health facility in their life time. Seventy five (19.2\%) of the mothers had history of still birth in their life time. One hundred seventy nine $(45.8 \%)$ of deliveries were not planned, the outcome of $367(93.9 \%)$ of deliveries was survived live births while the remaining $24(6.1 \%)$ we live births not survived. Vast majority, $350(89.5 \%)$ of deliveries were spontaneous vaginal delivery, and $332(84.9 \%)$ of mothers had normal health condition immediately after delivery. Two hundred twenty three $(57.0 \%)$ of deliveries took place during day time, only $30(7.7 \%)$ were referred to other facilities for further investigation and care (Table 2).

Table 2. Obstetric history of study participants, Omo Nada district, South West Ethiopia July 2014.

\begin{tabular}{|c|c|c|c|}
\hline Obstetric Characteristics & & Frequency & Percent (\%) \\
\hline \multirow{4}{*}{ Total Number of Children (Parity) $\mathrm{n}=(391)$ Mean $( \pm S D)$ of parity } & One & 78 & 19.9 \\
\hline & Two - Four & 223 & 76.7 \\
\hline & \multirow{2}{*}{ Five and above } & 90 & 11.8 \\
\hline & & $3.1( \pm 1.7)$ & \\
\hline \multirow{3}{*}{ Number of Children delivered at Health Facility $n=(391)$} & One & 298 & 76.2 \\
\hline & Two & 89 & 22.8 \\
\hline & Three and above & 4 & 1.0 \\
\hline \multirow{2}{*}{ History of Still Birth $n=(391)$} & Yes & 75 & 19.2 \\
\hline & No & 316 & 80.8 \\
\hline \multirow{3}{*}{ Place of still birth $n=(75)$} & At home & 56 & 74.6 \\
\hline & At Health Center & 11 & 14.7 \\
\hline & At Hospital & 8 & 10.7 \\
\hline \multirow{2}{*}{ Duration of Labour $\mathrm{n}=(391)$} & Less than 12 hours & 268 & 68.5 \\
\hline & More than 12 hours & 123 & 31.5 \\
\hline \multirow{3}{*}{ Mode of Delivery $n=(391)$} & Spontaneous Vaginal Delivery & 350 & 89.5 \\
\hline & Assisted Delivery & 37 & 9.5 \\
\hline & Cesarean Section & 4 & 1.0 \\
\hline \multirow{3}{*}{ Health condition of the mother immediately after delivery, $\mathrm{n}=(391)$} & Normal & 332 & 84.9 \\
\hline & Moderately Sick & 53 & 13.6 \\
\hline & Very Sick & 6 & 1.5 \\
\hline \multirow{2}{*}{ Fetal Outcome, $\mathrm{n}=(391)$} & Live birth survived & 367 & 93.9 \\
\hline & Live birth not survived & 24 & 6.1 \\
\hline \multirow{2}{*}{ Time of Delivery, $\mathrm{n}=(391)$} & Day time & 223 & 57.0 \\
\hline & At night & 168 & 43.0 \\
\hline \multirow{2}{*}{ Planned status of the pregnancy, $n=(391)$} & Planed & 212 & 54.2 \\
\hline & Not planed & 179 & 45.8 \\
\hline \multirow{2}{*}{ Referral during the last delivery, $\mathrm{n}=(391)$} & Referred & 30 & 7.7 \\
\hline & Not referred & 361 & 92.3 \\
\hline
\end{tabular}


Majority of mothers, 350 (89.5\%) had received ANC service for their last delivery; and out of the total mothers who had ANC attendance about 135(34.5\%) had three visits and $5(1.3 \%)$ had only one ANC visit during the last pregnancy. One hundred sixty eight $(43 \%)$ of mothers decided their place of delivery by themselves, and decisions given by their husband and family accounts 93(23.8\%) and $52(13.3 \%)$ respectively. One fourth of mothers that are included in this study used MWH service during their last pregnancy. Of the total mothers admitted to MWH 87(87.0\%) of them will recommend their friends or relatives to use the service in the future (Table 3).

Table 3. Antenatal Care and Maternity Waiting Home Service Utilization of Study Participants, Omo Nada district, south west Ethiopia, July 2014.

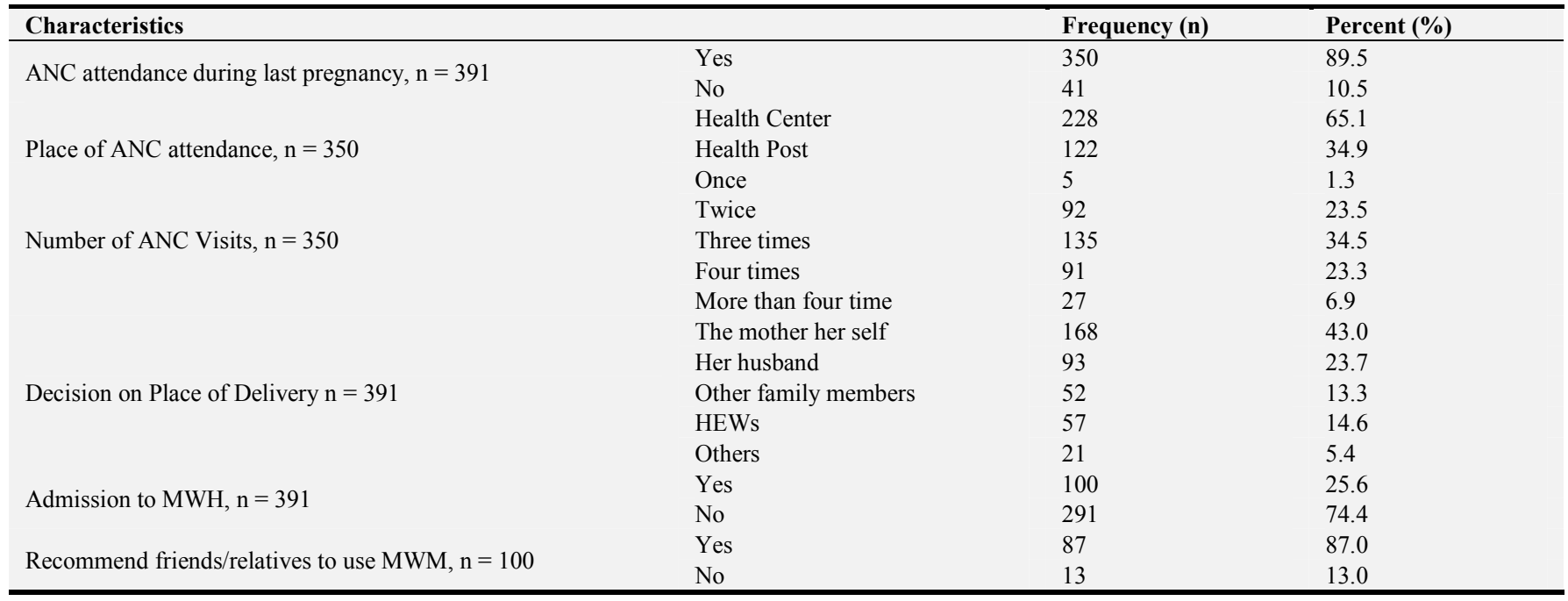

Three hundred thirty three $(85.2 \%)$ believed that the delivery room was clean while they received the service. Majority of the mothers $297(76.0 \%)$ were attended by female delivery attendant, and only $94(24.0 \%)$ of births were attended by male attendants, of the total mothers attended by male 31(33.0\%) were not comfortable for being the provider is male (Table 4$)$.

Table 4. Cleanliness of facilities and convenience with the sex of birth attendant in Omo Nada district, south west Ethiopia, July 2014.

\begin{tabular}{|c|c|c|c|}
\hline Variables & & Frequency (n) & Percent (\%) \\
\hline \multirow{2}{*}{ Cleanliness of Delivery room, $\mathrm{n}=391$} & Clean & 333 & 85.2 \\
\hline & Not Clean & 58 & 14.8 \\
\hline \multirow{4}{*}{ Cleanliness of the toilet during delivery care $n=391$} & Yes & 105 & 26.9 \\
\hline & Partially clean & 110 & 28.1 \\
\hline & Not clean & 76 & 19.4 \\
\hline & Did not used it & 100 & 25.6 \\
\hline \multirow{2}{*}{ Sex of Birth attendant, $\mathrm{n}=391$} & Male & 94 & 24.0 \\
\hline & Female & 297 & 76.0 \\
\hline \multirow{2}{*}{ Comfort being attended by Male $n=391$} & Comfortable & 63 & 67.0 \\
\hline & Not Comfortable & 31 & 33.0 \\
\hline
\end{tabular}

\subsection{Mothers' Level of Satisfaction}

Mothers' satisfaction with different aspects of institutional delivery service: provider manner $\&$ supportiveness, delivery care process, and condition of the facility were assessed using 14 satisfaction items that have five point Likert scale (Table 5).

Respondents' level of satisfaction with Supportiveness of the provider during delivery care process varies from strongly satisfied $94(24.0 \%)$, satisfied $231(59.1 \%)$ to not satisfied $14(3.6 \%)$. Mothers' satisfaction with privacy of delivery care was, 98(25.1\%) Strongly satisfied and 6(1.5\%) strongly not satisfied. Respondents' satisfaction with cleanliness of the delivery room in which the delivery was conducted was 56(14.3\%) Strongly satisfied and 266(65.3\%) satisfied.

Considerable number of mothers were not satisfied with availability of water; $142(36.3 \%)$ and $21(5.4 \%)$ were not satisfied and Strongly not satisfied with water supply in the Health centers they have received institutional delivery service. Besides, more than quarter of mothers were not satisfied and strongly not satisfied with the distance of $\mathrm{HC}$ from their residence, whereas about $117(45.5 \%)$ mothers were satisfied and $96(29.9 \%)$ of them are neither satisfied nor Unsatisfied (Table 5). 
Table 5. Mothers' level of satisfaction with different aspects of Institutional Delivery Service in Omo Nada district, south west Ethiopia, July 2014.

\begin{tabular}{llllll}
\hline Items/Variables (n=391) & $\begin{array}{l}\text { Strongly Satisfied } \\
\mathbf{n}(\%)\end{array}$ & Satisfied n(\%) & $\begin{array}{l}\text { Neutral } \\
\mathbf{n}(\%)\end{array}$ & $\begin{array}{l}\text { Not Satisfied } \\
\mathbf{n}(\%)\end{array}$ & $\begin{array}{l}\text { Strongly Not } \\
\text { Satisfied n(\%) }\end{array}$ \\
\hline Satisfaction with providers' manner and supportiveness during care process & & & & \\
Behavior of the SBA & $74(18.9)$ & $287(73.4)$ & $17(4.3)$ & $12(3.1)$ & $1(0.3)$ \\
Providers communication & $92(23.5)$ & $269(68.8)$ & $19(4.9)$ & $10(2.6)$ & $1(0.3)$ \\
Supportiveness of the provider & $94(24.0)$ & $231(59.1)$ & $51(13.0)$ & $14(3.6)$ & $1(0.3)$ \\
Attention given by the birth attendant and other staffs & $74(18.9)$ & $240(61.4)$ & $54(19.9)$ & $23(5.9)$ & $0(0.0)$ \\
Satisfaction with services and care process & & & & & $6(1.5)$ \\
Privacy of delivery care process & $98(25.1)$ & $225(57.5)$ & $49(12.5)$ & $13(3.3)$ & $0(0.0)$ \\
Convenience with physical examination process & $66(16.9)$ & $226(57.8)$ & $82(21.0)$ & $17(4.3)$ & $0(0.0)$ \\
Information received about the care process & $65(16.6)$ & $221(56.5)$ & $89(22.8)$ & $16(4.1)$ & $0(0.0)$ \\
Satisfaction with services provided in MWH & $14(13.9)$ & $42(41.6)$ & $29(28.7)$ & $16(15.8)$ & \\
Satisfaction with condition of the facility & & & & & $11(2.8)$ \\
Cleanliness of delivery room \& examination area & $56(14.3)$ & $255(65.2)$ & $42(10.7)$ & $27(6.9)$ & $21(7.3)$ \\
Cleanliness of toilet & $36(12.5)$ & $88(30.6)$ & $68(23.6)$ & $75(26.0)$ & $21(5.4)$ \\
Availability of water for drinking and bathing & $15(3.8)$ & $73(18.7)$ & $140(35.8)$ & $142(36.3)$ & $2(0.8)$ \\
Availability of required drugs and medical supplies & $63(16.1)$ & $223(57.0)$ & $56(14.3)$ & $46(11.8)$ & $3(0.0)$ \\
Condition of the HC (building \& equipment) & $91(23.3)$ & $232(59.3)$ & $58(14.8)$ & $10(2.6)$ & $38(9.7)$ \\
Distance of HC from place of residence & $60(15.3)$ & $118(30.2)$ & $117(29.9)$ & $58(14.8)$ & 3 \\
\hline
\end{tabular}

Overall satisfaction was computed by adding the mean score of 14 satisfaction items, the maximum total satisfaction score was 69 and the minimum was 31 score. The threshold score for satisfaction was determined using demarcation threshold formula, which is \{total highest score-total lowest score) $/ 2\}+$ Total lowest score. The threshold value for satisfaction was 50 and mothers with total score more than 50 were categorized as satisfied. A total of $255(65.2 \%)$ mothers scored satisfaction core of more than 50 , and categorized as satisfied with overall institutional delivery service and the remaining 136(34.8\%) were not satisfied.

\subsection{Factors Associated with Mothers' Satisfaction}

Bivariate and multivariate logistic regression analysis were conducted to see presence of association, and to measure relative effect of each independent variables on overall satisfaction. Age of the mother, wanted status of the pregnancy, cleanliness of the toilet, ANC utilization, admission to MWH, estimated walking distance and time of delivery were significant factors associated with mothers' overall satisfaction.

Table 6. Predictors of Mothers' Satisfaction with Institutional Delivery Service in Omo Nada district, south west Ethiopia, July 2014.

\begin{tabular}{llllll}
\hline Predictors of client satisfaction $(\mathbf{n}=\mathbf{3 9 1})$ & Satisfied & Not satisfied & COR $(\mathbf{9 5 \%}$ CI) & AOR (95\% CI) \\
\hline \multirow{4}{*}{ Age of the mother } & $<20$ Years & 41 & 4 & $12.20(3.75,25.68)^{* *}$ & $12.66(2.71,29.25)^{* *}$ \\
& $20-34$ Years & 193 & 107 & $2.15(1.15,4.02)^{* *}$ & $1.44(1.03,3.30)^{* *}$ \\
& $34-49$ Years & 21 & 25 & $1.00^{*}$ & $1.00^{*}$ \\
Parity & One & 51 & 27 & $1.31(0.70,2.47)$ & $0.19(0.08,0.49)^{* *}$ \\
& Two - Four & 151 & 72 & $1.46(0.88,2.43)$ & $0.85(0.43,1.70)$ \\
Wanted status of pregnancy & Five \& above & 53 & 37 & $1.00^{*}$ & $1.00^{*}$ \\
ANC attendance & Planed & 158 & 54 & $2.47(1.61,3.80)^{* *}$ & $2.85(1.56,5.21)^{* *}$ \\
& Not planed & 97 & 82 & $1.00^{*}$ & $1.00^{*}$ \\
Time of delivery & Yes & 236 & 114 & $2.34(1.25,4.61)^{* *}$ & $2.05(1.33,4.75)^{* *}$ \\
\multirow{5}{*}{ Admission to MWH } & No & 19 & 22 & $1.00^{*}$ & $1.00^{*}$ \\
& Day & 159 & 64 & $1.86(1.22,2.84)^{* *}$ & $2.63(1.47,4.72)^{* *}$ \\
Estimated walking & Night & 96 & 72 & $1.00^{*}$ & $1.00^{*}$ \\
reach HC & Admitted & 58 & 42 & $1.52(0.95,2.42)$ & $1.96(1.10,3.83)^{* *}$ \\
& Not admitted & 197 & 94 & $1.00^{*}$ & $1.00^{*}$ \\
& $<30$ minutes & 126 & 24 & $4.30(2.01,9.20)^{* *}$ & $10.48(3.78,19.06)^{* *}$ \\
Cleanliness of the toilet & $30-60$ minutes & 72 & 53 & $1.56(0.76,3.22)$ & $1.74(0.72,4.21)$ \\
& $61-90$ minutes & 25 & 51 & $0.40(0.18,0.90)^{* *}$ & $0.45(0.8,1.11)$ \\
& $>90$ minutes & 22 & 18 & $1.00^{*}$ & $1.00^{*}$ \\
\hline
\end{tabular}

** Statistically significant, $1.00 *$ reference group 
Mothers' age was significant predictor of their satisfaction with the service, those whose age is less than $20[\mathrm{AOR}=12.66$ with $95 \%$ CI $(2.71,29.25)]$ and mothers $20-34$ years of age $[\mathrm{AOR}=1.44$ with $95 \% \mathrm{CI}(1.03,3.30)]$ were more likely to be satisfied compared to those within 34-49 years of age group. Mothers who planned their pregnancy were 2.85 times more likely to be satisfied with institutional delivery service compared to those did not planned, [AOR=2.85 with $95 \% \mathrm{CI}(1.56,5.21)]$. Compared to mothers delivered at night time, those who gave birth during the day time are 2.6 times more likely satisfied, $[\mathrm{AOR}=2.6$ with $95 \% \mathrm{CI}(1.47,4.72)]$. Cleanliness of toilet during delivery service was also significant predictor of satisfaction $[\mathrm{AOR}=0.13$ with $95 \% \mathrm{CI}(0.06,0.30)]$.

The other important predictor of mothers' satisfaction with institutional delivery service was distance; mothers who reside in 30 minute walking distance radius to the $\mathrm{HC}$ are 10.48 times more likely to be satisfied by institutional delivery service compared to those living above 90 minute walking distance radius, $[\mathrm{AOR}=10.48$ with $95 \% \mathrm{CI}(3.78$, 29.06)]. This study also revealed mothers who had ANC follow up had two fold increased satisfaction compared to those did not receive ANC service, $[\mathrm{AOR}=2.05$ with $95 \% \mathrm{CI}$ $(1.33,4.75)]$. Mothers who had been admitted to MWH had increased satisfaction compared to those not admitted, [AOR $=1.96$ with $95 \% \mathrm{CI}(1.00,3.83)]$ (Table 6).

\section{Discussion}

This study showed the overall satisfaction of mothers with institutional delivery service was $62.8 \%$, which is very low compared to other findings of similar studies conducted in Wolaita 82.3\% [23] and Mekele 95\% [24]. This discrepancy may be due to difference in literacy of respondents, cultural diversity, satisfaction items and the techniques used to compute overall satisfaction. Since mothers who gave birth in the past six months prior to this study were included, satisfaction rating may also be affected by recall bias.

Planned status of the pregnancy was significant predicator of satisfaction, mothers who planned their pregnancy were 2.85 times more likely satisfied than those did not planned, $[\mathrm{AOR}=2.85$ with $95 \% \mathrm{CI}(1.56,5.21)]$. The study conducted in Amhara region referral hospitals also showed women's satisfaction with delivery care was associated with wanted status of the pregnancy [AOR $=2.2,95 \% \mathrm{CI}: 1.2,3.93)]$ [25]. Those findings are in line with the study finding from Kenya, on mothers satisfaction with delivery service, the adjusted odds of satisfaction with delivery care was higher for women with a wanted pregnancy $[\mathrm{AOR}=2.75,95 \%$ CI $(1.82,4.14)]$ [26]. Tough it is difficult to identify cause and effect, all these evidences show mothers who planned their pregnancy tend to have better satisfaction with delivery service they receive from health facilities. On the other hand, having planned pregnancy may be linked with better knowledge and awareness of health services as well as familiarity with health facilities prior to delivery service.

Our finding also revealed that ANC attendance had positive effect on satisfaction. Mothers who had ANC follow up had two fold increased satisfaction compared to those did not receive ANC service, $\mathrm{AOR}=2.05$ with 95\% CI (1.33, 4.75). Another similar study conducted in Assella Hospital, Ethiopia, also showed having prenatal visit was strong predictor mothers' satisfaction with delivery service [27]. Mothers who used ANC service will have opportunity to know their delivery attendant, this may help to create smooth environment in which providers and mothers become friendly during delivery care process.

Distance is one of determining factors identified in this study, mothers located at less than 30 minute walking distance from the $\mathrm{HC}$ had 10.48 times increased satisfaction compared to those coming from above 90 minute walking distance. The descriptive analysis also showed only $178(45 \%)$ of the respondents were satisfied with the distance they travelled to reach the HC they used for delivery service. In line with our finding, different studies identified that geographical accessibility of health facility as factor that affect utilization and satisfaction of mothers with institutional delivery service $[15,28,29]$.

Mothers who used MWH service prior to their delivery had $96 \%$ increased satisfaction, compared to those did not used the service. Utilization of MWH will increase mothers' satisfaction with delivery service by creating home like environment, breaking distance barrier to access health facility during labor and by building good relationship between service provider and mother.

\section{Conclusion}

This study concludes low mothers' satisfaction with institutional delivery service provided in public health centers of the district. Distances to reach the $\mathrm{HC}$ and availability of water during delivery were major sources of dissatisfaction; while provider communication and behavior were major sources of satisfaction.

Distance, ANC attendance, utilization of $\mathrm{MWH}$ service and wanted status of the pregnancy, were significant predicators of mothers' satisfaction with the service. Utilization of MWH and ANC service increases mothers' satisfaction with institutional delivery service. Mothers who planned the pregnancy were more satisfied with institutional delivery service compared to those did not plan. The study also detected presence of high unintended pregnancy among study participants; this gives a clue about the presence of unmated need or poor implementation of family planning service in the area. We recommend further comprehensive studies that assess family planning utilization in the area.

\section{References}

[1] Mengesha ZB, Biks GA, Ayele TA, Tessema GA. Determinants of skilled attendance for delivery in Northwest Ethiopia: a community based nested case control study. BMC Public Health [Internet]. BMC Public Health; 2013;13 (1): 1-6. Available from: http://www.biomedcentral.com/1471-2458/13/130. 
[2] Vieira C, Portela A, Miller T, Coast E, Leone T, Marston C. Increasing the Use of Skilled Health Personnel Where Traditional Birth Attendants Were Providers of Childbirth Care : A Systematic Review. J plose one [Internet]. 2012;7 (10): 1-9. Available from:

http://www.plosone.org/article/fetchObject.action?uri=info $\% 3$ Adoi\%2F10.1371\%2Fjournal.pone.0047946\&representation= PDF.

[3] L VL, Stekelenburg J, J VR. Maternity waiting facilities for improving maternal and neonatal outcome in low-resource countries (Review). Wiley Publ [Internet]. 2009; (3): 16. Available from:

http://share.eldoc.ub.rug.nl/FILES/root2/2009/Matewafaf/van _Lonkhuijzen_2009_Cochrane.pdf.

[4] Tsegay Y, Gebrehiwot T, Goicolea I, Edin K, Lemma H, Sebastian MS. Determinants of antenatal and delivery care utilization in Tigray region, Ethiopia : a cross-sectional study. $2013 ; 1-10$.

[5] Requejo J, Bryce J, Starrs A, Care F, Lawn J, Presern C, et al. Building a Future for Women and Children, count down to 2015 Maternal, Newborn and child survival, The 2012 Report. Geneva: WHO \& UNICEF; 2012 p. 1-288.

[6] WHO. " Skilled birth attendance in the developing world in comparison with the developed world. Consequences to the mother and child mortality. Where do we stand nowadays ?" [Internet]. 2008 p. 1-16. Available from:

http://crisis.med.uoa.gr/elibrary/12.pdf.

[7] Mehari AM. Levels and Determinants of Use of Institutional Delivery Care Services among Women of Childbearing Age in Ethiopia: Analysis of EDHS 2000 and 2005 Data [WP83]. Maryland, USA; 2013 p. 1-38. Report No.: 83.

[8] WHO Department of Reproductive Health. Factsheet Proportion of births attended by a skilled attendant - 2007 updates Factsheet. WHO; 2013.

[9] Central Statistical Agency and ICF International. Ethiopia Demographic and Health Survey 2011. Addis abeba; 2012 p. $1-450$.

[10] UNFPA. Trends inMaternal Health in Ethiopia Challenges in achieving the MDG for maternal mortality In-depth. Addis Ababa; 2012 p. 1-78.

[11] Awoke W, Muhammed J, Abeje G. Institutional delivery service utilization in Woldia, Ethiopia. Sci J Public Heal. 2013; 1 (1): 18-23.

[12] WHO/UNICEF/UNFPA. Women-friendly health services Experiences in maternal care. Mexico; 1999.

[13] FMoH. NATIONAL GUIDELINE FOR FAMILY PLANNING Federal Democratic Republic of Ethiopia. Addis Ababa: FMoH; 2011.p. 1-69.

[14] Central Statistical Agency and ICF International. Ethiopian Demogrphic nd Helth survey. 2011.

[15] Birhanu Z, Assefa T, Woldie M, Morankar S. Determinants of satisfaction with health care provider interactions at health centres in central Ethiopia: a cross sectional study. BMC Health Serv Res. 2010; 10 (78).
[16] Belachew T. Client Satisfaction, Primary Health Care \& Utilization of services in Sidama district,. 2001. p. 1-50.

[17] UNICEF. Maternal and Newborn Health [Internet]. New York: United Nations Children's Fund (UNICEF); 2009. Available from: http://www.unicef.org/sowc09/docs/SOWC09FullReport-EN.pdf.

[18] Khanam N, Syed ZQ, Wagh V. Patient Satisfaction on Maternal and Child Health Services. Ind Med Gaz. 2012;2 (11): 47-51.

[19] Health Strategy Implementation Project. Measurement of Patient Satisfaction Guidelines Measurement of Patient Satisfaction [Internet]. Irish Society for Quality and Saftey in Health Care; 2003. p. 37. Available from: http://www.dohc.ie/issues/health_strategy/action48.pdf?direct $=1$.

[20] Omo Nada Woreda Health Office. Annual Health Care Report of Omo Nada Woreda Health office in the 2005 EFY. 2013.

[21] Akhtari-zavare M, Hassan STS, Said SB, Kamali M. Patient Satisfaction: Evaluating Nursing Care for Patients Hospitalized with Cancer in Tehran Teaching Hospitals, Iran. Glob J Health Sci. 2010;2 (1): 117-26.

[22] Taye TM and B. Patients satisfaction with laboratory services at antiretroviral therapy clinics in public hospitals,Ethiopia. BMC Res Notes. 2012; 5 (184).

[23] Yohannes B, Tarekegn M, Paulos W. Mothers "Utilization Of Antenatal Care And Their Satisfaction With Delivery Services In Selected Public Health Facilities Of Wolaita Zone, Southern Ethiopia: NTERNATIONAL J Sci Technol Res. 2013; 2 (2): 74-85.

[24] Abay T. Assessment of Utilization of Skilled Birth Attendant at Delivery in Mekelle town, northern Ethiopia. Addis abeba University; 2007. p. 94.

[25] Tayelgn A, Zegeye DT, Kebede Y. Mothers' satisfaction with referral hospital delivery service in Amhara Region, Ethiopia. BMC Pregnancy Childbirth [Internet]. BioMed Central Ltd; 2011; 11 (1): 78. Available from: http://www.biomedcentral.com/1471-2393/11/78.

[26] Bazant EVAS, Koenig MA. Women' s satisfaction with delivery care in Nairobi's informal settlements. Int J Qual Heal Care [Internet]. 2009;21 (2): 79-86. Available from: Available at http://intqhc.oxfordjournals.org/.

[27] Amdemichael R, Tafa M, Fekadu H. Gynecology \& Obstetrics Maternal Satisfaction with the Delivery Services in Assela Hospital, Arsi. 2014; 4 (12). Available from: http:/omicsonline.org/open-access/maternal-satisfaction-withthe-delivery-services-in-assela-hospital,pdf.

[28] Haymanot Mezmur, Berhanu Desalegn AS. Factors Affecting Choice of Delivery Place among Women in Haramaya Woreda, Oromia Regional State, Eastern. PHARMA Innov - J. 2013; 2 (10): 59-69.

[29] Willis L, Montoro-gurich C, Bloom S, Fortney J, Robinson J. A framework for the evaluation of quality of care in maternity service [Internet]. Southhampton: University of Southhampton; 2000. p. 40. Available from: www.socstats.soton.ac.uk/choices/. 